\title{
A VIOLÊNCIA VERBAL E NÃO VERBAL: UM EMPECILHO PARA O PROCESSO DE ENSINO E APRENDIZAGEM
}

\author{
Ariele Helena Holz Nunes \\ Gabriela Elenita Tureck \\ Marly Krüger de Pesce
}

Submetido em 31 de maio de 2019.

Aceito para publicação em 18 de agosto de 2019.

Cadernos do IL, Porto Alegre, n. ${ }^{\circ}$ 59, outubro. p. 307-324.

\section{POLÍTICA DE DIREITO AUTORAL}

Autores que publicam nesta revista concordam com os seguintes termos:

1. Os autores mantêm os direitos autorais e concedem à revista o direito de primeira publicação, com o trabalho simultaneamente licenciado sob a Creative Commons Attribution License, permitindo o compartilhamento do trabalho com reconhecimento da autoria do trabalho e publicação inicial nesta revista.

2. Os autores têm autorização para assumir contratos adicionais separadamente, para distribuição não exclusiva da versão do trabalho publicada nesta revista (ex.: publicar em repositório institucional ou como capítulo de livro), com reconhecimento de autoria e publicação inicial nesta revista.

3. Os autores têm permissão e são estimulados a publicar e distribuir seu trabalho online (ex.: em repositórios institucionais ou na sua página pessoal) a qualquer ponto antes ou durante o processo editorial, já que isso pode gerar alterações produtivas, bem como aumentar o impacto e a citação do trabalho publicado.

4. Os autores estão conscientes de que a revista não se responsabiliza pela solicitação ou pelo pagamento de direitos autorais referentes às imagens incorporadas ao artigo. A obtenção de autorização para a publicação de imagens, de autoria do próprio autor do artigo ou de terceiros, é de responsabilidade do autor. Por esta razão, para todos os artigos que contenham imagens, o autor deve ter uma autorização do uso da imagem, sem qualquer ônus financeiro para os Cadernos do IL.

POLÍTICA DE ACESSO LIVRE

Esta revista oferece acesso livre imediato ao seu conteúdo, seguindo o princípio de que disponibilizar gratuitamente o conhecimento científico ao público proporciona sua democratização.

http://seer.ufrgs.br/cadernosdoil/index

Terça-feira, 29 de outubro de 2019. 


\title{
A VIOLÊNCIA VERBAL E NÃO VERBAL: UM EMPECILHO PARA O PROCESSO DE ENSINO E APRENDIZAGEM
}

\author{
VERBAL AND NON-VERBAL VIOLENCE: A PLEDGE \\ FOR THE TEACHING AND LEARNING PROCESS
}

\author{
Ariele Helena Holz Nunes* \\ Gabriela Elenita Tureck** \\ Marly Krüger de Pesce***
}

RESUMO: Objetiva-se por meio deste artigo analisar a construção do discurso político-pedagógico acerca da dimensão da violência no aparato escolar, sobretudo, nas imediações da sala de aula. Para tanto, o apoio teórico foi buscado em Foucault (2000), Fairclough (2008), Orlandi (2001), entre outros. Considerando que na contemporaneidade os casos de violência envolvendo o corpo discente e docente da instituição escola estão crescendo em grande escala, foi questionado, especialmente, em que medida a violência verbal e não verbal interfere no processo de ensino e aprendizagem. Os resultados sugerem que a escola, enquanto espaço da diversidade, recebe sujeitos com particularidades e pertencentes a realidades distintas, os quais apresentam condutas inadequadas durante os processos de interação com o outro e o mundo.

PALAVRAS-CHAVE: violência; escola; ensino e aprendizagem; análise do discurso.

\begin{abstract}
The objective of this work is to analyze the construction of the political-pedagogical discourse about the dimension of violence in the school apparatus, especially in the classroom. For this purpose, theoretical support was searched in Foucault (2000), Fairclough (2008), Orlandi (2001), among others. Considering that in contemporary times the cases of violence involving the student body and teacher of the school institution are growing on a large scale, it was questioned, especially, how the verbal and nonverbal violence interferes in teaching and learning process. The results suggest that the school, as a space of diversity, receives subjects with particularities and belonging to different realities, who present inadequate behaviors during the processes of interaction with the other and the world.
\end{abstract}

KEYWORDS: violence; school; teaching and learning; speech analysis.

\section{Introdução}

$\mathrm{Na}$ contemporaneidade, o conceito de violência escolar foi expandido, saindo do âmbito da punição do professor para com o aluno e passando a ser constatada também, de aluno para aluno e de aluno para com o professor. Sendo assim, novas tipologias de violência começaram a ser detectadas, de modo que ficou em evidência que um dos

\footnotetext{
* Mestranda em Linguística pela Universidade Federal de Santa Catarina, holz.ariele@gmail.com.

** Graduanda em Língua Portuguesa e Língua Inglesa pela Universidade da Região de Joinville, gabi.elenitatureck@gmail.com.

*** Professora no Mestrado em Educação e no curso de Letras da Universidade da Região de Joinville, doutora em Educação pela PUC/SP, marlykrugerdepesce@gmail.com.
} 
grandes empecilhos dos processos de ensino em aprendizagem construídos em ambiente escolar é a violência verbal e a não verbal, já que são registrados casos com maior recorrência, recebendo mais polaridade no meio social.

Nesse sentido, tomando como panorama a atual situação da educação brasileira, há de ser considerado que o termo violência escolar é quase inexistente nesse universo. Ainda que não sejam registrados casos de agressão e de abuso de linguagem em todos os contextos de ensino, é muito comum que sejam divulgadas notícias nos diversos veículos de comunicação em massa envolvendo alunos, professores e coordenação pedagógica em situações de violência na instituição escola. No entanto, é importante destacar que mesmo com toda essa perspectiva de denúncia circulando pela sociedade, pouco se analisam essas práticas de violência que ocorrem no aparato escolar, e, simultaneamente, nem sempre se dá voz a todos os envolvidos, fazendo com que a escola reafirme o seu papel de sistema de restrição do discurso, defendido por Foucault (2000).

À vista disso, discute-se a temática a violência verbal $e$ não verbal: um empecilho para o processo de ensino e aprendizagem, buscando analisar a construção do discurso político-pedagógico acerca da dimensão da violência no aparato escolar, sobretudo nas imediações da sala de aula a partir da questão motivadora: a) Em que medida a violência verbal e não verbal interfere no processo de ensino e aprendizagem?

Para tanto, realizou-se uma pesquisa quantitativa, cujo instrumento de coleta de dados foram entrevistas orais, e o processo de revisão da literatura, tendo como autores fundantes: Abramovay (2002), Assis (2010), Chesnais (1981), Charlot (1997), Debarbieux (1996), Foucault (2000), Fairclough (2008), Orlandi (2001), entre outros. Além disso, algumas considerações também bebem de fontes como livros organizados pelo Governo Federal, entre eles o intitulado: Impactos da violência nas escolas (ASSIS, 2010), que visa conscientizar a população acerca dessa problemática recorrente na sociedade.

Consideradas essas questões, acresce mencionar que este trabalho encontra sua significância à medida que busca compreender como a violência é contornada no ambiente escolar e, ao mesmo tempo, quais os impactos desse fenômeno para os processos de ensino e aprendizagem, atendo-se à fala de docentes de contextos distintos, os quais constroem discursos singulares acerca desse problema social. A investigação também encontra o seu propósito ao observar se a existência de situações recorrentes de violência acarreta a desmotivação do profissional docente e, consequentemente, a desestruturação do sistema escolar na sua totalidade.

Sendo assim, o presente artigo segue uma estrutura pré-estabelecida, discutindo, no primeiro momento, algumas considerações teóricas acerca do termo violência escolar, destacando as tipologias desse fenômeno, bem como as significações presentes nessas práticas agressivas. Posteriormente, os dados da pesquisa são discutidos e analisados, com base nos autores fundantes do trabalho e de alguns teóricos complementares. Em um terceiro momento, são explicados os procedimentos metodológicos detalhadamente e, por fim, algumas considerações finais sobre os resultados e a experiência são traçadas.

Consciente de que esta é uma pesquisa principiante, salienta-se que outros estudos ainda serão realizados sobre o tema, podendo gerar resultados diferentes mediante a experimentação de outros referenciais teórico-metodológicos. No entanto, destaca-se que o trabalho desenvolvido apresenta a sua significância aos estudiosos da área da educação, em especial àqueles que buscam a construção de um fazer pedagógico 
mais humanístico e de uma escola que acolha os sujeitos em aprendizagem e não os discrimine. Assim, há uma necessidade de ampliação do tema, devido a sua relevância social, que ultrapassa os muros da escola.

\section{Algumas considerações}

Historicamente, a violência escolar sempre esteve relacionada aos atos punitivos praticados pelos professores em relação aos alunos indisciplinados, de modo que o corpo discente não era reconhecido como agressor, praticante tanto da violência física quanto verbal. As significações semânticas atribuídas ao termo violência foram expandidas com o decorrer do tempo, fazendo com que diferentes níveis e tipos de violência passassem a ser discutidos no ambiente escolar e para além dele, como bem escreve Debarbieux (1996 apud Abramovay, 2002, p.64): "Uma lição essencial da história poderia ser esta variabilidade de sentidos da violência na educação, correlacionada às representações da infância e da educação'.

Seguindo essa linha, Chesnais (1981 apud Abramovay, 2002) destaca três tipos de violência existentes nas imediações do aparato escolar, podendo ser praticados dentro ou fora das salas de aula. Para o autor, na contemporaneidade as práticas de violência são mais comuns entre os próprios alunos, fazendo com que os casos de violência que partem do aluno para o professor ou do professor para o aluno sejam constatados em menor proporção. Explica-se esse fato à medida em que os alunos ainda estão em estágio de formação em determinados anos da escolarização, acarretando, muitas vezes, na não consciência de seus atos e percepção de que o seu fazer enquanto sujeito atuante da sociedade pode atingir a liberdade, o espaço e a integridade do outro.

Partindo da concepção de que a multiplicidade de violência deve ser hierarquizada mediante o seu custo social, a primeira tipologia a ser destacada é a violência física. Essencialmente a mais visível na sociedade, essa prática resulta em danos irreparáveis aos indivíduos envolvidos, sobretudo à vítima. Incluindo a violência sexual, que também ocorre no espaço escolar e requer alguma intervenção da sociedade, bem como medidas reparadoras ligadas ao Estado. Assim sendo, a violência física é a que "significaria efetivamente a agressão contra as pessoas, já que ameaça o que elas têm de mais precioso: a vida, a saúde, a liberdade" (Chesnais, 1981, p.14 apud Abramovay, 2002, p.66).

A segunda tipologia, denominada como violência econômica, está particularmente ligada à depredação de patrimônio, incluindo atos de delinquência e criminalidade contra os bens materiais, reconhecidos como práticas de vandalismo. Conforme Chesnais (1981 apud Abramovay, 2002), essa especificação de violência não apresenta consequências tão preocupantes, como as ligadas à violência física, já que não ferem a integridade de determinado indivíduo, mas ainda assim devem ser consideradas como um empecilho alarmante durante o processo de ensino e aprendizagem.

A terceira concepção de violência se relaciona com a ideia de autoridade, do abuso da linguagem, apresentando indícios de subjetividade, cuja denominação é violência moral ou violência simbólica. Trata-se da violência verbal, a qual atinge os indivíduos através da combinação de palavras ofensivas, embutidas de preconceitos e de discursos não humanísticos. Nas teorizações de Salles et al (2010, p.218):

A violência não pode ser reduzida ao plano físico, podendo se manifestar também por signos, preconceitos, metáforas, desenhos, isto é, por qualquer coisa que possa ser interpretada como aviso de ameaça. [...] Nas escolas, 
segundo os professores, a violência está aumentando não somente do ponto de vista quantitativo como também do qualitativo. Os tipos de violência assinalados por eles como estando mais presentes no dia a dia escolar são as ameaças e agressões verbais entre alunos e entre estes e os adultos. Os professores em seus relatos têm destacado que a violência, principalmente o desrespeito, é uma constante no meio escolar (SALLES et al, 2010, p.218).

Complementando, Charlot (1997 apud Abramovay, 2002) discorre sobre a dificuldade em definir os atos de violência escolar, especialmente porque são fenômenos muito particulares, difíceis de ordenar, que devem ser analisados a partir do contexto do ocorrido. Além disso, o autor pontua que são atos que desestruturam a dinâmica do ambiente escolar, fazendo com que as representações sociais de infância como período de inocência, a de escola enquanto um refúgio de paz e da própria sociedade sendo pacífica, caiam por terra.

Ainda nesse âmbito, Charlot (1997 apud Abramovay, 2002) amplia o conceito de violência escolar, delimitando-a em três níveis distintos, que se assemelham aos conceitos apresentados por Chesnais (1981 apud Abramovay, 2002). O primeiro nível é intitulado como violência, incluindo a ocorrência de atos como: golpes, ferimentos, violência sexual, roubos, crimes e vandalismo no ambiente escolar. Alternando um pouco a natureza da violência, o segundo nível compreende situações de humilhação, de trocas de palavras grosseiras, ou ainda, de falta de respeito, sendo chamada pelo autor de incivilidades. Em uma última instância, destaca-se a violência simbólica ou institucional, cuja natureza apresenta uma multiplicidade de sentidos, podendo ser compreendida como:

[...] a falta de sentido de permanecer na escola por tantos anos; o ensino como um desprazer, que obriga o jovem a aprender matérias e conteúdos alheios aos seus interesses; as imposições de uma sociedade que não sabe acolher os seus jovens no mercado de trabalho; a violência das relações de poder entre professores e alunos. Também é a negação da identidade e satisfação profissional aos professores, a sua obrigação de suportar o absentismo e a indiferença dos alunos (CHARLOT, 1997 apud ABRAMOVAY, 2002, p.66).

Independentemente do tipo de manifestação de violência escolar, de modo geral, essas práticas que ocorrem nas imediações da instituição escola, e podem ser consideradas, sobretudo, uma ruptura com a ordem social, a quebra de diálogo e de negociações entre os indivíduos, fazendo com que os mesmos transgridam aos atos físicos ou simbólicos, quaisquer que sejam. Especificando, Sposito (1998, p.60 apud Abramovay, 2002, p.69) denuncia: "[...] violência é todo ato que implica a ruptura de um nexo social pelo uso da força. Nega-se, assim, a possibilidade da relação social que se instala pela comunicação, pelo uso da palavra, pelo diálogo e pelo conflito".

Acresce mencionar que há correntes que sustentam a ideia de que a violência é exterior ao ambiente escolar, sendo assim, apenas executada nesse espaço, uma vez que o problema social é projetado para além dos muros da escola, decorrente de outros fatores que não dizem respeito à transmissão de saberes científicos, mas às problemáticas que permeiam a sociedade há algumas décadas, tais como: a ação de gangues criminosas, o tráfico de drogas, a xenofobia, o racismo, a homofobia e ainda o bullying, cuja iniciação se dá, muitas vezes, no bojo familiar.

Nessa perspectiva, a vulnerabilidade da escola frente às inúmeras tipologias de violência já é consensual na sociedade contemporânea. Uma justificativa é o fato dessa instituição estar perdendo aos poucos a sua legitimidade enquanto espaço de 
transmissão de saberes de diferentes áreas de conhecimento. Autores como Payet (1997, p.145 apud Abramovay, 2002, p.75) se ocupam dessa questão, como bem assinala:

A violência na escola, enquanto objeto social, se inscreve em diversos locais. Os estabelecimentos escolares têm certamente o status de lugar original, mas o "problema social" é construído em outros cenários. Entre esses, a cena midiática e política são determinantes, pois elas dão aos atos, aos incidentes, um porte e um valor gerais, que por sua vez dão sentido ao que se passa nos estabelecimentos. [...] Essa maneira de "pensamento único" sobre a violência na escola pode ser resumida a algumas evidências. A violência que se manifesta na escola provém do exterior. Para que a violência cesse, é necessário fechar a escola, protegê-la, isolá-la (PAYET, 1997, p.145 apud ABRAMOVAY, 2002, p.75).

Do mesmo modo que a violência é exteriorizada, colocando a escola como o ambiente em que ela apenas reflete uma realidade que os alunos carregam em si, essa instituição também é o espaço em que se propicia a disseminação dessas práticas. Tratase de um autoritarismo pedagógico que desperta as condutas violentas dos alunos, proveniente de relações conturbadas entre corpo discente e docente. Comportamentos repressivos por parte dos educadores, a utilização de metodologias que dificultam a aprendizagem por opção, os atos punitivos e a distância da linguagem dos estudantes são indicadores para a promoção da violência em sala de aula, em especial, a violência simbólica, que parte da verbalização entre os indivíduos.

Assim sendo, a instituição escola não deve ser postulada apenas como reprodutora das experiências de opressão, de conflito, de desordem, provenientes do plano macrossocial. Nesse sentido, é importante argumentar que as escolas também produzem a sua própria violência:

A escola, com sua educação tradicional, impõe ao aluno um aprendizado que não corresponde à sua realidade e universo cultural, sendo vista de uma forma negativa e nada estimulante e lúdica. $\mathrm{O}$ seu controle exagerado estimula sentimentos de rebeldia e desobediência... A violência que as crianças e os adolescentes exercem é, antes de tudo, a que o seu meio exerce sobre eles. Sabemos que a escola-caserna é vivida como um lugar trancado que impõe aos corpos uma ordem de uniforme, da qual não há meio de fugir: regras, controles, punições, dominações são os meios habituais de disciplina. A escola tem se mostrado com frequência como espaço e coação. Parece ter ficado do lado de fora o caminho lúdico da aprendizagem (SANTOS, 1999, p.156).

Retomando a ideia de que a violência que a criança exerce na escola é, muitas vezes, um reflexo das práticas que são exercidas com elas primeiramente, faz-se necessário salientar que a violência familiar é um dos principais fenômenos que desencadeiam condutas violentas no ambiente escolar, especialmente porque muitos dos meninos e meninas que estão nesse espaço não sabem onde canalizar o seu sofrimento ou confidenciar as suas problemáticas a alguém.

Esse tipo de violência é exercido, principalmente, contra crianças, adolescentes e mulheres. Segundo Assis (2010), por violência familiar entende-se toda ação ou omissão cometida por um membro de determinada família que prejudique o bem-estar, a integridade física, psicológica ou os direitos que garantem o pleno desenvolvimento de outro membro familiar. A violência familiar pode ser praticada dentro ou fora de casa, por um membro da família próximo, ou por parentes sem laços de 
consanguinidade, os quais passam a assumir alguma função parental.

Embora essas questões não sejam efetivamente abordadas em cursos de formação continuada para professores e gestores escolares, é função da escola agir sobre todo e qualquer tipo de violência, já que tanto a violência familiar quanto qualquer outra trazem dificuldades ao cotidiano escolar, uma vez que a escola "[...] não está imune a seus reflexos e suas consequências e também pode contribuir para aumentá-la quando reproduz desigualdades e formas de tratamento indevidas" (ASSIS, 2010, p.152).

Tomando como princípio a concepção de Foucault (2000) de que a escola não passa de mais um sistema de restrição do discurso, o qual ritualiza as palavras, distribui e apropria os dizeres de acordo com a sua necessidade, qualifica e fixa os papéis dos indivíduos que falam no seu interior, além de estar em consenso com a ação de um grupo doutrinário sobre um menos difuso, acresce mencionar que, em contrapartida, ainda é pela linguagem que o sistema escolar consegue contornar a violência dentro das suas imediações.

Dessa maneira, Fairclough (2008, p.91) trabalha com o discurso enquanto prática social, defendendo que o mesmo não serve apenas para representar o mundo, mas, fundamentalmente, é uma forma de agir sobre a realidade em que se está inserido e sobre o outro:

\begin{abstract}
Ao usar o termo 'discurso', proponho considerar o uso de linguagem como forma de prática social e não como atividade puramente individual ou reflexo de variáveis situacionais.(...) Implica ser o discurso um modo de ação, uma forma em que as pessoas podem agir sobre o mundo e especialmente sobre os outros, como também um modo de representação (FAIRCLOUGH, 2008, p.91).
\end{abstract}

Repensando que o discurso é uma forma de agir sobre o outro, frente a situações de violência na instituição escola, o discurso pode ser utilizado como um meio de fazer com que os agressores compreendam que a sua conduta não está sendo adequada, já que desestrutura o andamento da comunidade escolar e, também, interfere nos processos de ensino e aprendizagem, provocando uma defasagem durante a transmissão de conhecimentos.

À vista disso, ao mesmo tempo em que o discurso deve ser utilizado para estabelecer uma relação com o agressor no espaço escolar, também deve ser dada a ele a possibilidade de se expressar, de se comunicar, apresentando os motivos para que determinada situação tenha transitado da indisciplina para práticas extremas no ambiente em que devem ser realizadas trocas significativas, as quais apenas a escolarização proporciona.

Ademais, nas lições de Orlandi (2001, p.128), o discurso carrega diferentes tipos de silêncios, os quais possibilitam interpretações acerca do que está sendo dito:

O silêncio tem suas formas. Distinguimos pelo menos duas formas de silêncio. 1. Silêncio fundador, aquele que e necessário aos sentidos: sem silêncio não há sentido. É o silêncio que existe nas palavras, que as atravessa, que significa o não dito e que dá espaço de recuo significante, produzindo as condições para significar. O silêncio como horizonte, como iminência do sentido, é a respiração da significação para que o sentido faça sentido. 2. Política do silêncio [...] que nos indica que para dizer é preciso não dizer, em outras palavras, todo dizer apaga necessariamente outras palavras produzindo um silêncio sobre outros sentidos (ORLANDI, 2001, p.128).

O silêncio, definido por Orlandi (2007) como a respiração da significação, pode 
ser entendido, dentro de um contexto escolar violento, como uma carta aberta aos educadores, isto porque, sem grandes dificuldades, quando o aluno vem de um quadro de ações violentas e silencia, não tece explicações e tampouco argumenta em seu favor, diz muito sem nem mesmo lançar uma palavra. Os vocábulos são naturalmente atravessados pelo silêncio. Isso significaria elucidar que os sentidos que são silenciados no discurso se deslocam para outro movimento simbólico: o da necessidade de intervenção quando a existência do não dizer se faz mais presente do que a do dizer.

Concomitantemente, dentro da discursividade o silêncio é visto como um recuo necessário à significação, é incorporado como um dos potencializadores da construção de sentidos. A sua existência é proposital. Em Orlandi (1993, p.14) se tem a noção de silêncio enquanto recurso excepcional da discursividade:

\begin{abstract}
Silêncio que atravessa as palavras, que existe entre elas, ou que indica que o sentido pode sempre ser outro, ou ainda que aquilo que é mais importante nunca se diz, todos esses modos de existir dos sentidos e do silêncio nos levam a colocar que o silêncio é "fundante". Assim, quando dizemos que há silêncio nas palavras, estamos dizendo que elas são atravessadas de silêncio; elas produzem silêncio; o silêncio "fala" por elas; elas silenciam. As palavras são cheias de sentidos a não dizer e, além disso, colocamos no silêncio muitas delas (ORLANDI, 1993, p.14).
\end{abstract}

Utilizar-se da análise do discurso para mergulhar nas práticas que sustentam ações violentas não é um processo de extração de conteúdo e forma. Esmiuçar a discursividade está muito mais ligado à extração da materialidade do discurso enquanto um fenômeno de constituição de sentidos, de sujeitos e de interlocutores. Para Orlandi (2007, p.91), a análise do discurso trabalha com "processos de constituição filiados a redes de significação".

Por consequência, no que tange às justificativas para atos de violência, se é que sejam possíveis, nem sempre elas trarão motivos explícitos. Ater-se ao não dito defendido pela autora é uma maneira de analisar a situação de violência escolar como um todo, contemplando também a perspectiva do agressor, que muitas vezes está apenas trazendo para o ambiente escolar um reflexo dos dilemas que enfrenta para além dos muros da escola.

\title{
3 Princípios metodológicos
}

Sabendo que o propósito do presente artigo é analisar criticamente a influência da violência verbal e não verbal no processo de ensino e aprendizagem, a escolha metodológica se explica à medida que a discursividade só pode ser explorada através do contato com o próprio discurso. Reconhecendo esses aspectos como cruciais, o instrumento de coleta de dados corresponde a entrevistas orais com duas professoras de língua portuguesa atuantes na rede municipal de ensino das cidades de Joinville e São Bento do Sul (Santa Catarina), ambas com experiências distintas na educação básica. Com a iniciativa de manter o anonimato das respondentes, conforme solicitado pelas informantes, a identificação fica por conta de pseudônimos: P1 remete a primeira entrevistada e $\mathrm{P} 2$, é o nome dado à segunda participante.

Desta forma, acresce mencionar que P1 atua tanto em ambientes universitários, sendo professora de graduação, quanto na educação básica, lecionando para os anos finais do ensino fundamental, o que lhe soma trinta e três anos de experiência na 
profissão docente. Diferentemente, P2 está no início da carreira, mas também leciona para os anos finais do ensino fundamental, tendo aproximadamente um ano de experiência, o que proporciona um contraste bastante grande em relação às falas de $\mathrm{P} 1$. Oriundas de contextos diferentes, as docentes expuseram discursos político-pedagógicos distintos e passíveis de análise por diferentes ângulos, já que carregam significações divergentes e marcas discursivas próprias da sua subjetividade.

Nessa perspectiva, esta forma de abordar o sujeito da pesquisa partiu de um roteiro semiestruturado de perguntas acerca da temática em investigação. Em muitos momentos, esse direcionamento possibilitou um norte à fala dos participantes, cujos discursos construídos nem sempre conseguiram responder aos questionamentos de uma forma linear, fugindo, em alguns casos, da linha de raciocínio proposta pelo entrevistador.

Assim sendo, a entrevista foi orientada por cinco questões motivadoras, como podem ser evidenciadas a seguir: a) Você acredita que a violência, tanto física quanto verbal, influencia no processo de ensino e aprendizagem? Por quê?; b) Ao identificar um aluno que possui determinada conduta violenta, você realiza algum trabalho pedagógico com o tema?; c) Determinadas situações de violência podem acarretar a desmotivação do profissional docente? Justifique; d) Pensando em longo prazo, quais os malefícios que esses tipos de violência podem trazer caso não seja tomada alguma medida de contenção?; e) Quais os meios para contornar a violência em sala de aula?

A natureza qualitativa do estudo explica-se à medida em que a experiência de pesquisa parte da singularidade dos sujeitos respondentes e das vivências coletivas realizadas por ambos no meio em que estão inseridos. Sendo assim, os relatos apresentados nas entrevistas não foram qualificados como verdadeiros ou falsos, já que são interpretações ou representações do mundo, e não podem ser comprovados através de métodos quantitativos, assim como o intuito não era atribuir-lhes juízo de valor algum.

Recorrer a esse tipo de referencial metodológico é um exercício interessante para compreender a função do campo discursivo no todo sincrético produzido pelos diferentes indivíduos na sociedade. Todo sujeito é marcado por uma ideologia, assim como carrega teorizações científicas e mundanas singulares, o que demanda construir um olhar para a enunciação e não propriamente para uma gama de dados fechados. Em função disso, o cruzamento entre a violência e a análise do discurso que ultrapassa os limites das estatísticas revela uma possibilidade de pesquisa diferente, cuja amplitude vai muito além das próprias ações praticadas pelos agressores e seus respectivos discursos.

\section{Análise e discussão dos dados}

Em uma primeira instância, serão discutidas as questões de números 1, 3 e 4, que objetivaram identificar os malefícios promovidos pela ocorrência de atos violentos, verbais e físicos dentro do espaço da sala de aula. Em específico, a primeira questão buscou a constatação do ponto de vista do profissional docente em relação às consequências negativas que a violência pode acarretar para o processo de ensino e aprendizagem, identificando não somente a concordância ou a discordância demonstrada pelo professor mas também a justificativa que demonstre como ocorre esta intervenção para com as práticas agressivas em sala de aula.

No que concerne o primeiro questionamento, este era de caráter subjetivo. Assim 
sendo, formulou-se a seguinte pergunta: "Você acredita que a violência, tanto física quanto verbal, influencia no processo de ensino e aprendizagem? Por quê?". A resposta obtida de P1 (2017) na referida indagação demonstrou uma afirmação positiva de que há uma interferência significativa no ensino ao se tratar de cenários de violência em sala de aula, conforme segue:

\begin{abstract}
Ah sim, interfere. Se for com a professora porque há uma, vai haver uma discussão, vai haver uma, é.... Eu acho até que um certo autoritarismo porque não dá para aceitar algumas questões, né? Violência principalmente verbal em sala de aula. A física eu nem, nem consigo te mencionar porque eu não passei ainda por essa experiência. Graças a Deus. Mas há uma questão de violência tanto física quanto verbal com relação aos colegas. Muito maior do que com o professor. Desde bullying, ah com questões de desrespeito, mesmo brincadeiras de mau gosto e agressões mesmo. Às vezes um ponta pé, um chute. $\mathrm{O}$ aluno que é agredido ele não consegue aprender e o aluno que agride ele tem essa, essa agressividade que também não faz focar no ensino. Então, a violência e ensino não caminham juntas (P1, 2017).
\end{abstract}

Partindo da premissa existencial do impacto causado pela violência em sala aula, Charlot (1997), conforme já mencionado no aporte teórico, faz a distinção de três níveis, sendo eles: violência, incivilidade e institucional. Diante desse cenário, nota-se que no discurso de P1 há indícios de que a docente lida mais no seu cotidiano escolar com violência em nível de incivilidade em detrimento das demais faces que este fenômeno pode apresentar.

Acresce ainda mencionar que dentro do nível de incivilidade, o bullying se faz bastante presente, sendo este identificado por Marriel et al (web, 2006) como todo ato de opressão ofensivo e, até mesmo, de agressão que um indivíduo pratica em relação a outro. Vale salientar que na prática do bullying há o estabelecimento de um opressor e de uma vítima, caracterizando-se assim, em um processo envolvendo relações de poder. Para ambos os componentes nesta ação, segundo P1, o processo de aprendizagem é prejudicado. Tal assertiva pode ser elucidada por Marriel et al (web, 2006).

De maneira geral, a violência manifesta uma afirmação de poder sobre o outro e a conquista desse poder é o que gera as diversas formas de violência. Suas ocorrências são consequência das práticas cotidianas de discriminação, preconceito, da crise de autoridade do mundo adulto ou da fraca capacidade demonstrada pelos profissionais de criar mecanismos justos e democráticos de gestão da vida escolar (MARRIEL et al, web, 2006).

Ainda no âmbito do primeiro questionamento, cabe serem evidenciados os efeitos construtivos do discurso em sala de aula. Notou-se que o respondente P1, ao trazer em sua fala as seguintes palavras "Eu acho até que um certo autoritarismo porque não dá pra aceitar algumas questões, né?", reitera o discurso como prática social. Conforme já mencionado no embasamento teórico, o discurso enquanto prática social estabelece uma relação de poder em relação ao outro e também, a sua realidade. Legitimando essa afirmação, Fairclough (2008) trabalha com a concepção de discurso enquanto meio de representar a realidade e, simultaneamente, modificá-la e agir sobre o outro.

Dialogando com a problemática apresentada, Foucault (2000, p.44) explicita que "todo sistema de educação é uma maneira política de manter ou de modificar a apropriação dos discursos, com os saberes e os poderes que eles trazem consigo". À 
vista disso, o discurso disseminado pelo professor possui também um cunho de modelagem em relação aos discursos dos alunos. Em um cenário de violência, o discurso se apresenta assim como uma forma de mediação e de contornar as práticas agressivas nas imediações da sala de aula.

Ainda seguindo esta lógica, P2 (2017) apresentou a seguinte afirmação como resposta:

É... que acredito que influencia bastante. Eu acho que as duas, tanto uma quanto a outra, elas, as duas prejudicam. Mas acho que a violência física é a que é mais marcante no ensino. Porque a verbal é..., eles (os alunos) às vezes pensam que levam na brincadeira e acabam é..., passa mais despercebida a verbal. Já a física não. A física tem um impacto maior para a turma, para toda a instituição. E... parece que não tem mais o clima, parece que na hora que você vai aprender, vai ensinar, é... não desenvolve porque fica a cena na cabeça. Já a linguagem verbal não, a linguagem verbal você vai..., vai vim outras coisas, outros pensamentos e vai embora a linguagem verbal. Você acaba esquecendo. Já a física tem a linguagem na memória, a cena na memória, né? (P2, 2017).

Igualmente, é importante colocar em discussão a ênfase exposta na fala de P2 ao tratar da violência física "[...] tem um impacto maior para a turma para toda a instituição. [...]". A constatação da docente estabelece um contraponto em relação à fala de P1, uma vez que o enfoque é direcionado à violência física. Desta forma, para P2, a violência física possui um custo social maior do que a violência verbal.

A divergência entre P1 e P2 pode ser analisada sob o viés de diversos aspectos exteriores que condicionam o cenário de violência na sala aula. Relembrando as teorizações apresentadas nas considerações teóricas, pode-se dizer que, para Payet (1997, p.145), diversas vezes a violência aparece em sala de aula. Porém, como a representação de um fator exterior ao ambiente escolar, tal como os problemas sociais enfrentados no bojo familiar, que possuem uma influência direta no espaço escolar, bem como, o contexto em que a instituição está inserida. Em outras palavras, em decorrência da localidade e do índice de violência na comunidade, algumas práticas agressivas podem refletir nas imediações do aparato escolar.

Ao tratar da questão de número 3, que tinha como intuito investigar de que maneira o cenário de violência pode culminar na desmotivação do professor, objetivamos ainda identificar diferenças entre as concepções do profissional que está iniciando a carreira daquele que está inserido no âmbito da docência há alguns anos. Assim sendo, foi proposto o seguinte questionamento: "Determinadas situações de violência podem acarretar a desmotivação do profissional docente? Justifique".

A partir dos relatos dos respondentes, observou-se que a desmotivação em decorrência de situações recorrentes de violência faz parte, por vezes, da carreira na docência, sobretudo na sua fase inicial, o que podemos destacar pelas falas de P1 e P2, respectivamente:

[...] (pausa) Eu não sofro muita violência, nem física, nem verbal. Não sofri e não sofro. E... é..., eu não... não acredito que isso iria desmotivar o professor. Assim, para a questão do ensino. Mas, eu acho que se essas situações forem recorrentes, com o tempo, sim. Então, um aluno desrespeitar em algum momento, falar algum palavrão... Eu não sei como seria essa violência verbal com o professor, né? Agredir verbalmente. Eu acho que num primeiro momento ele consegue contornar, porque ainda é o adulto da relação. Então, tem que usar isso como uma forma educativa muito mais do que punitiva. Se o professor se deixar levar por uma situação ou outra, é complicado. Mas estou falando de situações não recorrentes, tá? Agora, acho 
que quando chega num limite, sim. Acho que emocionalmente, questões de saúde do docente, pode levar sim, não só à desmotivação como a não ter mais, não ensinar, não planejar bem uma aula, se afastar daquela atividade e até desistir da profissão docente. Não são raros os casos em que professores desistem de ser professores em função das condições de trabalho e isso entra a saúde do professor. E algumas questões não dependem do aluno e sim de um sistema todo. Mas há algumas pesquisas que já falam que o professor quando está exposto à situações de violência, desiste mais facilmente da profissão docente, principalmente no início da carreira. $(\mathrm{P} 1,2017)$

Sim, bastante. É... comigo já aconteceu também, até pensar em desistir da carreira de ser professora, por motivos de violência. Tanto, não é só os alunos que sofrem com a violência, professor também sofre. E, principalmente, com a violência verbal. Porque os alunos, eles te xingam por trás, se não está bom aquilo para eles, eles começam a reclamar. Às vezes te xingam na tua frente e (pausa) e nada as vezes é feito. Né, então, isso te desmotiva extremamente. Então, tem salas que você sabe, ah tem tal aluno, meu deus que droga entrar naquela sala. Que aquele aluno, a gente vai começar a discutir, ele vai começa a reclamar e...ou se não, aquela sala só sabe se xingar. Aquela sala só sabe um bater no outro e assim por diante. Então, desmotiva muito na carreira do professor essa questão de violência, tanto entre os alunos como dos alunos para com o professor. (P2, 2017)

No que tange à desmotivação do docente, vale salientar que esse fenômeno, pela fala de P1, pode ser decorrente também de outros fatores, tais como saúde, condições do ambiente de trabalho ou até mesmo questões em relação ao sistema de ensino. Como forma de legitimar esse discurso, Batista et al (1999, p.150 apud Costa, 2011, p.222) identifica que "os episódios de violência nas escolas começam a afetar a saúde mental dos professores, na medida em que eles se tornam recorrentes e passam efetivamente a formar parte da realidade do trabalho nas escolas". Partindo dessa premissa, nota-se que a agressividade na sala de aula condiciona um quadro de mal-estar no profissional docente, devido ao enfrentamento que este profissional passa no cotidiano escolar.

Seguindo outro viés de análise, desta vez no âmbito conversacional, acresce ainda mencionar que a pausa feita por P1 antes de proferir sua resposta pode também ser analisada em alusão a uma das máximas conversacionais de Grice (1982), que se refere à qualidade daquilo que é dito: não diga o que você acredita ser falso.

A pausa nesse aspeto configuraria em uma possível incerteza do falante em relação ao enunciado produzido, bem como o uso do advérbio "né" frequentemente. De acordo com o dicionário Michaelis (2017), o advérbio "né" indica um pedido de confirmação ou concordância. Ora a incerteza pode estar relacionada com a não veracidade dos enunciados, ora pode ser um vício de linguagem adotado por P1 e P2 ao fazer uso da oralidade.

Recorrendo à discursividade novamente, é possível notar que o discurso de ambas é atravessado por um não dito com uma significância importante: a enunciação falsa. Apesar de fazerem uso de argumentos plausíveis para defender os seus pontos de vista, as docentes revelam que, no caso de P1, o seu discurso demonstra incerteza quando se refere a sua experiência docente, mas assume validade ao passo que a violência se insere em um curso natural quando envolve o outro; já no que se refere à P2, há uma modalização explícita no seu dizer, demonstrando a necessidade do outro entendê-lo como verídico, ainda que não seja.

Adentrando em mais resultados, no item de número 4 foi proposta a abordagem dos malefícios a longo prazo que a violência em sala de aula pode trazer. Procurou-se, 
assim, a identificação de alguns desses malefícios através da visão do docente. Logo, estabeleceu-se o seguinte questionamento: "Pensando em longo prazo, quais os malefícios que esses tipos de violência podem trazer, caso não seja tomado alguma medida de contenção'. P1 (2017) relatou:

\begin{abstract}
Ah, acho que para o aluno é a questão do processo de aprendizagem. Ele acaba não aprendendo, tanto para quem sofre a agressão, a violência, quanto para quem pratica essa violência. Sem contar questões de atitudes. Quer dizer, vai para o mercado de trabalho, na rua vai brigar, vai agredir, vai apanhar, vai preso. Há consequências com relação aos atos que talvez a escola nem sempre dê conta. Ou que não consegue trabalhar. Às vezes, extremistas demais. Com relação ao professor, acho que é realmente o abandono da função docente. Acho que chega num momento que ele diz que não, não quero isso para mim, vai acabar. Por isso que é importante a formação continuada e então, você entende o que está acontecendo. E pensa, né, em ações que consigam amenizar isso. Então, refletir sobre o que está acontecendo e propor ações de como se trabalhar vai amenizar, vai né, deixar tanto para o professor quanto para os alunos uma questão mais amena. Embora que a longo prazo, eu acho que as consequências são bem sérias (P1, 2017).
\end{abstract}

Ao revisitarmos o conceito de política do silêncio de Orlandi (2001), no qual o dito traz implícito um não-dito, e este por sua vez possui outras significações, P1 ao trazer o comentário: "Quer dizer, vai para o mercado de trabalho, na rua vai brigar, vai agredir, vai apanhar, vai preso" promove uma possível significação do não dito, oportunizando a interpretação que aqueles alunos que tiveram histórico violento na sua vida escolar necessariamente passarão pelas mesmas situações em outras instâncias da sociedade.

Essa significação se dá, principalmente, pela estreita relação de dependência entre o dito e o não dito. Claramente, em todo discurso, há uma margem de não-ditos que também possuem significados, considerados pela autora o espaço em que o sentido ultrapassa a dimensão das próprias palavras explícitas. Observando por esse viés, embora o discurso proferido por P1 não caracterize uma intenção direta de condicionar o comportamento do aluno violento a um "potencial meliante", há outros dizeres que atravessam o seu dito, perpassando o seu controle subjetivo de significação.

Ao passo que P2 (2017) apresentou em sua fala:

Eu acho que o resultado a gente já está vendo um pouco por aí. A gente vê em jornais, né? Principalmente em redes sociais sobre toda violência que tem sido causada. Então, desde aluno saindo batendo em professor, colegas, né... Atirando por aí. Fazendo outros maus. Eu acho que se algo não for feito de imediato, não for trabalhado, não uma semana, não um mês, mas se não trabalhado de uma forma contínua, todo dia, sempre, o ano inteiro. Todo o ano letivo estar trabalhando em cima daquela questão, eu acho que tem a tendência a só piorar. E, esse não é um trabalho só do professor, é um trabalho da instituição, tipo. Não adianta só eu trabalhar na aula de Língua Portuguesa, é..., um artigo de opinião, uma coisa assim relacionada à violência, tanto verbal quanto física. Eu acho que tem que ser um trabalho em conjunto com a instituição, da escola junto com os outros professores e a comunidade também. Além dos pais, né. Porque se ele vem com essa violência, algo acarreta no familiar também. Então, é um trabalho em conjunto, não um trabalho do professor sozinho (P2, 2017).

No relato feito por P2, há uma abordagem voltada à conscientização dos 
malefícios que a violência escolar traz, de modo que foi colocado como um passo importante nesse processo a realização de trabalhos com a temática de maneira contínua, e a partir de uma relação estreita com todas as disciplinas do currículo. Desse modo, a resposta de $\mathrm{P} 2$ reafirma a necessidade de um ensino interdisciplinar e de caráter social, que também promova a participação e a interação da comunidade nos contextos de ensino.

Ademais, a questão de número 2 faz o seguinte apontamento: "Ao identificar um aluno que possui determinada conduta violenta, você realiza algum trabalho pedagógico com o tema? Por exemplo, propor um artigo de opinião, debates, seminários etc.'. Ambas as respondentes relataram que trabalham com a temática em sala de aula, com o objetivo de promover uma conscientização entre os alunos de que as condutas agressivas adotadas por eles não são condizentes com o ambiente escolar. Foi também citada a existência do profissional orientador educacional, que contribui, em muitos casos, com a reversão e a amenização da conduta violenta de determinados indivíduos. Portanto, postula-se que o trabalho, em função da diminuição da violência no espaço escolar, apresenta uma demanda para além dos espaços da sala de aula tradicional:

\footnotetext{
[...] (pausa) É..., sim eu realizo. Eu tenho uma turma de oitavo ano que eles são violentos assim, tanto na questão física como na questão verbal. Então eles se xingam muito, questão de racismo, preconceito um com o outro. Chamam o outro de macaco, chamam o outro de preto, nego, lixo e nomes pra cima disso. E ah..., eles se intimidam assim. Alguns tentam levar na brincadeira, mas acabam se ofendendo de um outro modo. Então, é, teve cenas que não teve como não fazer alguma coisa depois. Então, já trabalhei artigo de opinião, já abri para seminário, já abri para discussão. ("deixa eu ver se não vou responder a outra pergunta”). Já abri para discussão sim, várias... Vários meios de tentar convencê-los e..., tentar fazer eles se conscientizarem do que estão fazendo, né? (P2, 2017)
}

Sim. É...quando há situações, já relacionando com a questão anterior, quando há relações de violência tanto verbal quanto física, a escola tem um papel, principalmente, nesse processo todo, que é o de trabalhar, de achar meios de fazer com que eles entendam que aquela atitude, ela não é adequada para aquele ambiente. Então, às vezes, por meio de um artigo de opinião, por exemplo, ou mesmo questionando se eles consideram aquela atitude correta ou não. Teatro, né, que eles consigam expressar porque eles têm toda aquela agressividade dentro deles. É claro que o aluno que agride ele, é..., ele chega na escola com algumas situações que né, de estrutura ou que a gente acaba não entendendo o porquê dessa agressividade. Nós temos que procurar sim o porquê. O que está acontecendo com ele. O professor como mediador de situações que envolvem essas agressões, a violência, ele consegue, em muitos casos, reverter ou até mesmo, ir diminuindo essas situações no dia a dia, cotidiano. Há um profissional na escola que é o orientador educacional e ele tem essa competência, né. Ele estudou para isso, para que consiga trabalhar. Mas o professor, ele pode sim, por meio de um gênero textual, de uma atividade, fazer um trabalho mais específico. Geralmente dá certo. (P1, 2017)

Por fim, a questão de número 5 tratou dos meios para contornar a violência em sala de aula: "Quais os meios para contornar a violência em sala de aula?". As duas entrevistas salientarem que o diálogo constitui a melhor forma de mediação, e que este deve ser tido como uma medida educativa e não de punição. Além disso, deve-se também, segundo as respondentes, analisar as situações que envolvem a violência como um todo, buscando identificar quais os motivos geradores do ato violento, para que 
assim possam ser tomadas outras medidas que priorizem o bem-estar de todos os envolvidos.

Embora as justificativas não sejam plausíveis para explicar o motivo da violência, faz-se necessário o estabelecimento de um diálogo entre aluno, professor e instituição. Vale ressaltar que a criação de políticas de diminuição da violência em parceria com os órgãos de grande representatividade no meio social pode contribuir significativamente para a reversão de muitos quadros, como bem evidencia P1 (2017):

\begin{abstract}
Acho que são questões educativas mesmo, tá? É uma conversa, é procurar entender, é mediar. É o professor, é buscar essa formação continuada para o... sabe... é por meio de leituras, de estudo, de discussão com os pares. Conversar com os outros professores, com a direção da escola, com os outros profissionais que estão envolvidos nesse processo todo. Acho que tudo isso ajuda. É tentar aproximar a família desse aluno na escola também, para ver como é que escola e família trabalham nessas situações, tá? E sempre propor ações que acho que vai ajudar esse aluno. Porque ele nem sempre, ele...é... como é que vou dizer, nem sempre ele é o único responsável pela situação, mas não quer dizer que ele não seja o responsável, porque ele também é responsável pela situação. Mas, nem sempre ele entende o que está acontecendo, porque ele está agindo daquela forma. Então, você tem que procurar trazer o aluno, entender o que está acontecendo e para isso conhecer e saber como vai fazer. Eu penso que políticas públicas, sabe, que ajudem, que resolvam algumas questões sociais, né? Que vai além dos muros da escola também são formas de se ajudar esse aluno e os professores. Então, se ele é uma criança que sofre maus tratos, que... tenha algumas questões de situações de risco em que está exposto, é claro que isso vai refletir na escola, né? Então, fora essa questão da escola, eu acredito que tem questões bem governamentais. Pensar em algumas políticas públicas de como tentar resolver essas questões sociais. Eu acho melhor em sala de aula. E pensar também em políticas para o professor, né? Que ele tenha condições de trabalho adequadas. Que ele consiga ter um tempo, apoio para buscar uma formação específica e possa se sentir valorizado por aquilo que ele faz e ter vontade de sempre estudar mais e buscar mais. $(\mathrm{P} 1,2017)$
\end{abstract}

Eu acho que como eu, né. Eu acho que reprimir o aluno, ficar só dando advertência, suspensão, eu acho que não é o melhor meio. Porque ele só vai mudar de escola, ele só vai mudar de vítimas. Ele só vai mudar o alvo dele. $\mathrm{E}$ ele, com certeza, ele vai procurar outras pessoas. Tem que achar um meio de conscientizar, um tratamento conforme for o nível da violência, né. Achar um meio de conscientizar esses alunos sobre o quão mal eles estão fazendo para os outros. Quanto isso pode prejudicar ele e o próximo. (P2, 2017)

Acerca das medidas punitivas em relação aos atos de violência, sabe-se de maneira geral que essas medidas, por vezes, podem acarretar agravantes para os quadros de violência, colocando a escola como produtora da violência entre alunos e professores. Resgatando o que já foi mencionado no aporte teórico, ao mesmo tempo que a escola recebe os reflexos de uma violência que é exterior ao seu espaço, ela também deve ser entendida como um meio que propaga as situações de violência, como elucida Santos (1999, p.156): "O seu controle exagerado estimula sentimentos de rebeldia e desobediência. [...] A violência que as crianças e os adolescentes exercem é, antes de tudo, a que o seu meio exerce sobre eles".

Orlandi (2007, p.87) complementa a discussão sobre o caráter punitivo, recorrendo aos seus respaldos dentro da discursividade, como bem escreve: “[...] é preciso acrescentar que uma sociedade como a nossa, pela sua constituição, pela sua 
organização e funcionamento, pensando-se o conjunto de suas práticas em sua materialidade, tende a produzir a dominância do discurso autoritário".

Concomitantemente, é notável através dos discursos político-pedagógicos de ambas as professoras que há uma influência prejudicial exercida pela violência em relação ao processo de ensino e aprendizagem. À medida que tais situações de violência, sejam elas verbais ou não-verbais, se instauram dentro da sala de aula, acarretam modificações abruptas e negativas ao ensino que desencadeiam, desde dificuldades em aprendizagem, relacionamento entre alunos e professores até a desmotivação do profissional docente.

\section{Conclusão}

A legitimação do discurso da violência, seja ele instaurado no âmbito dos vocábulos ou da própria simbologia discursiva tida como invisível, não deve ser incorporado e tampouco aceito como um elemento fundante e coparticipante do cotidiano escolar. Trocando os termos, a violência exercida pelos estudantes independe de sua tipologia, não pode ser absorvida como um processo natural, devendo ser investigada no seu cerne, a começar pelas marcas de seu contexto social e cultura que são expressas em seus discursos.

Ao longo da história, a análise do discurso assumiu diferentes caminhos para destrinchar e explorar criticamente as relações discursivas estabelecidas entre os indivíduos. Diante desse cenário, ao traçar a perspectiva do silêncio e da não enunciação naquilo que está dito, lança-se como um aporte teórico relevante para compreender os discursos que são atravessados pelos traços da violência. $O$ estudante que pratica ou apresenta indícios de atos violentos diz muito apenas com as suas ações, dispensando a própria enunciação. Igualmente, é possível que não diga nada com as suas palavras, criando enigmas que poucos conseguem decifrar, o que aumenta as chances de sua postura ser incompreendida em situações extremas.

O fazer docente também é marcado por traços discursivos específicos, e carrega em seu interior elementos que devem ser considerados quando o seu papel social é posto em xeque. Não só o discurso escolhido pelo próprio docente, como os discursos proferidos sobre ele são objetos passíveis de ponderações pautadas na criticidade. A violência dificilmente fará parte da conduta docente, mas pode ser um potencializador dos atos realizados pelos estudantes, assim como, em um movimento inverso, essas ações podem modificar a visão e o modo de operar e enunciar do professor.

No corpus da análise foi possível verificar que há uma concordância em relação ao papel influenciador e negativo da violência nos processos de ensino e aprendizagem. Tal nocividade afeta todos os envolvidos dentro do âmbito escolar. Sendo assim, tanto aquele que pratica, bem como aquele que é o alvo a ser atingido pela ação violenta, sofrem e são prejudicados. O produto dessas situações é refletido em sala de aula, em uma aprendizagem defasada.

Acresce ainda que a desmotivação do profissional docente também pode se originar em função do enfrentamento que o professor deve exercer dentro de sala de aula. Foi evidenciado que a desmotivação é mais passível de ocorrer no início da carreira do profissional, uma vez que este está buscando sua afirmação e auto reconhecimento dentro da profissão.

No entanto, nota-se que há uma divergência em relação ao custo social dos tipos de violência. Dentro de alguns espaços e determinadas visões, que por sua vez carregam 
experiências específicas, a violência verbal se apresenta como grande e majoritária vilã do ensino, sendo que a violência física parece quase não existir. Enquanto isso, em outros locais, a violência física possui um poder de impacto e ocorrência significativamente maior, assumindo, assim, um dos maiores desafios a serem vencidos em sala de aula.

À vista disso, a linguagem, aliada ao trabalho coletivo entre escola, pais, alunos e comunidades escolar, se apresenta como o meio mais eficaz de mudança e de reversão da violência. Deve existir um diálogo com caráter moderador entre as partes, buscando não somente amenizar os "ânimos", mas compreender o motivo pelo qual se deu a ocorrência do ato violento. $\mathrm{O}$ discurso do praticante da violência escolar possibilita, em alguns casos, a percepção de que aquele indivíduo necessita de intervenções pedagógicas, bem como que a violência apresentada na sala de aula, por vezes, é um reflexo de uma realidade exterior.

Tendo em conta esses fatores, torna-se imprescindível o refletir sobre a violência, o agir contra a violência. Negociar os conflitos e ignorá-los durante o processo de ensino e aprendizagem não os torna menores, invisíveis ou inexistentes, apenas contribui para que tenham consequências mais abrangentes à posteriori. Trabalhar continuamente, com articulação entre os diferentes profissionais que atuam na comunidade escolar, é um dos passos a ser dado. Inserir valores e ações reais no cotidiano dos sujeitos praticantes dos atos violentos, os quais assegurem condições concretas do viver, é o fechamento do ciclo a ser percorrido.

\section{REFERENCIAS}

ABRAMOVAY, Miriam; RUA, Maria das Graças. Violência nas escolas. Brasília: UNESCO, 2002.

ASSIS, Simone Gonçalves de. Impactos da violência nas escolas: um diálogo com professores. Rio de Janeiro: Ministério da Educação - MEC/ Editora Fiocruz, 2010.

BATISTA, Anália Sônia et al. Violência e agressão. In: CODO, Wanderley (Coord.). Educação: carinho e trabalho. Petrópolis: Vozes, 1999.

CHARLOT, Bernard; ÉMIN, Jean-Claude. Violence à l'école - et de savoirs. Paris: Massone Armand, 1997.

CHESNAIS, Jean-Claude. Histoire de la violence. Paris: Éditions Robert Laffont, 1981.

COSTA, Polyana A. da S. Violência no cotidiano escolar: a visão dos professores que atuam no ensino fundamental de escolas públicas do município de Corumbá-MS. 2011. 263f. Dissertação (Mestrado em Educação) - UFMS. Corumbá, 2011.

DERBABIEUX, Éric. La violence em millieu scolaire: l'etat des lieux. Paris: ESF éditeur, 1996.

FAIRCLOUGH, Normam. Discurso e mudança social. Brasília: Editora da Universidade de Brasília, 2008. 
FOUCAULT, Michel. A ordem do discurso. 6. ed. São Paulo: Loyola, 2000.

GRICE, H.P. Lógica e conversação. 1982. In: DASCAL, Marcelo. Fundamentos metodológicos da Linguística. São Paulo: UNICAMP, 1982.

MARRIEL, L. C. et al. Violência escolar e autoestima de adolescentes. NET. São Paulo, 2006. Disponível em: http://www.scielo.br/scielo.php?script=sci_arttext\&pid=S010015742006000100003. Acesso em 22/11/2017.

MICHAELIS 2017, Melhoramentos. Disponível em: http://michaelis.uol.com.br/. Acesso em 22/11/2017.

ORLANDI, E. P. As formas do silêncio: no movimento dos sentidos. Campinas: editora da Unicamp, 1993.

2001.

. Discurso e texto: formulação e circulação dos sentidos. São Paulo: Pontes, . Análise de discurso: princípios e procedimentos. $7^{\mathrm{a}}$ ed. Campinas: Pontes, 2007.

PAYET, Jean- Paul. Le Segregation Scolaire: Une perspective Sociologique sur la Violence à L'école. In. DERBABIEUX, Éric. La violence à L'école: Approaches Europeenes - Revue Françaice de Pedagogie, $n^{\circ} 123$, Institute National de Recherche Pedagogic, 1997.

SALLES, Leila Maria Ferreira et all. A violência na escola: abordagens teóricas e propostas de prevenção. Educar em Revista, n. 2, p. 217-232. Universidade Federal do Paraná: Paraná, 2010.

SANTOS, José Vicente Tavares. A palavra e o gesto emparedados: a violência na escola. PMPA, SMED, 1999.

SPOSITO, Marília Pontes. A instituição escolar e a violência. In. Cadernos de Pesquisa. São Paulo: Fundação Carlos Chagas, nº 104, p. 58-75, 1998. 